\title{
OUTCOME OF EJACULATION PRESERVING TRANS URETHRAL PROSTATECTOMY (EPTURP)
}

By

\section{Hany Mofid Zaher Hendy, Al-Sayed Mohamad Mousa and Yaser Ali Ahmad}

\author{
Department of Urology, Al-Azhar Faculty of Medicine (Cairo), Egypt
}

Corresponding author: Hany Mofid Zaher Hendy

Mobile: 01097559102; E-mail: hanygtu@gmail.com

\begin{abstract}
Background: Bladder outlet obstructions (BOO) are one of the major disorders in the aging male. The most common etiology of $\mathrm{BOO}$ in elderly men above the age of 60 years is benign prostatic hyperplasia, but younger men $(<50$ years old $)$ can also experience subvesical obstruction from a small but obstructive prostate. Surgical intervention (TURP) after failure of first-line treatment can achieve highly satisfying symptomatic and functional outcomes in patients with BOO. Retrograde ejaculation is one of the most common complications in benign prostatic hyperplasia (BPH) surgery. Surgeons are concerned about this complication when patients are sexually active.
\end{abstract}

Objective: To evaluate the efficacy of ejaculation preserving TURP (epTURP) in relation to functional results.

Patients and Methods: Thirty one patients with bladder outlet obstruction due to clinically diagnosed BPH were enrolled in our prospective study which was carried out at the Urology Department, Al-Azhar University, during the period from January 2017 to September 2019, undergoing (epTURP). They were evaluated for preservation of ante grade ejaculation along with the functional outcome of this technique after 1,3 , and 6 months of post-operative follow up.

Results: The complications such as stress incontinence, urethral stricture and bladder-neck contracture were not recorded in our studied patients. Three patients $(9.7 \%)$ did not ejaculate on follow up after epTURP at 1 , 3, 6 months. We considered the cause of insufficient preservation of the safety area of the ejaculatory ducts. In our cases, there was a failed case did not void after removal of catheter, and needed reintervention by traditional TURP. The decision of retreatment of the failed patient by traditional TURP was done by AlHussein Department after failure of epTURP to relieve BPH obstruction. We considered the cause as imperfect resection of the supra montanal tissue.

Conclusion: The epTURP technique developed with the aim of preserving ante grade ejaculation for patients with obstruction manifestations due to benign prostatic enlargement, with failure of medical treatment to relieve that obstruction, and those patients who hope of preserving ejaculation for sexual pleasure, psychological satisfaction, or to gain pregnancy. The results from this study may underline the necessity of reviewing the old concept of ejaculation physiology.

Keywords: Bladder outlet obstructions (BOO), benign prostatic hyperplasia (BPH), ejaculation preserving trans urethral resection of prostate (epTURP).

\section{INTRODUCTION}

Bladder outlet obstructions (BOO) are one of the major disorders in the aging male. The most common etiology of BOO in elderly men above the age of 60 years is benign prostatic hyperplasia, but younger men ( $<50$ years old) can also experience subvesical obstruction from a 
HANY M. HENDY et al.,

small but obstructive prostate (Dogan et al., 2011). Surgical intervention (TURP) after failure of first-line treatment can achieve highly satisfying symptomatic and functional outcomes in patients with BOO. Retrograde ejaculation is one of the most common complications in benign prostatic hyperplasia (BPH) surgery. Surgeons are concerned about this complication when patients are sexually active. Transurethral prostatectomy (TURP) causes retrograde ejaculation in up to $70 \%$ of cases. The use of alphareceptor antagonists is also known to possibility cause a loss in antegrade ejaculation (Gilling et al., 2018). However, clinical evidence has indicated that bladder neck closure may not be important for maintaining antegrade ejaculation (Paul et al, 2014). Clinical findings have shown patients with retrograde ejaculation after retroperitoneal lymphadenectomy for testis tumor with a closed bladder neck due to sympathatic chain injury (Hsiao et al., 2012).

Patients who sustain orthostatic ejaculation after prostate sparing cystectomy and neobladder formation (Girgin et al., 2013), implying that bladder neck closure may not be concerned with orthostatic ejaculation. The histopathological confirmation of the ejaculatory ducts and the surrounding ductus ejaculatorus, which is expected to have a major role for expulsion (Selman et $a l, 2011)$. On the basis of these new findings, modified techniques for ejaculation preservation have been introduced in BPH surgeries (Chandrasekera et al., 2012). All the approaches spare the ejaculatory hood, especially the sufficient supramontanal tissue, about $1 \mathrm{~cm}$ from the verumontanum. These observations identified the smooth muscle musculus ejaculatorius as a mandatory to the process of ejaculation (Saladin et al., 2014).

The present work aimed to evaluate the efficacy of ejaculation preserving TURP (epTURP) in relation to functional results.

\section{PATIENTS AND METHODS}

Thirty one patients with bladder outlet obstruction due to clinically diagnosed BPH were enrolled in the study which was carried out at the Urology Department, Al-Azhar University, during the period from January 2017 to September 2019.

Study design: A single-site, prospective, randomized clinical study.

Inclusion criteria: Male patients with enlarged prostate indicated for TURP, patients with severe lower urinary tract symptoms (LUTS) according to IPSS score, IPSS >14, Q max (maximum urinary flow rate) $\leq 10 \mathrm{ml} / \mathrm{second}$, plus failure of medical treatment for symptoms of $\mathrm{BPH}$, and sexually active with antegrade ejaculation.

Exclusion criteria: Major psychiatric and somatic diseases and the use of drugs that affect sexual function, patients with impaired erection, patients with no ejaculation, patients with documented or suspected prostate cancer, patients with neurogenic bladder, voiding dysfuntion, urethral strictures and malignancies of the upper or lower urinary tract, prostates sized more than $80 \mathrm{CC}$, severe comorbidities; as abnormal coagulation profile, or high surgical risk patients. 
All patients were submitted to a detailed evaluation including: Detailed medical history, physical examination, digital rectal examination, focused neurologic examination, international prostate symptoms score (I-PSS-0/35), before and after epTURP, quality of life bothersome score (0/6), International Index of Erectile Function (IIEF), before and after epTURP, uroflowmetry, before and after epTURP, laboratory tests: urine analysis, culture and sensitivity tests, if needed, semen volume estimation, before and after epTURP, plus other routine preoperative laboratory tests.

We categorized the ejaculation results as 'no change', 'decreased' or 'vanished'. The success of ejaculation preservation was defined as the 'no change' or 'decreased' but subjectively considerable antegrade ejaculate state at the last followup.

Imaging tools: Ultrasound of the abdomen and pelvis. To measure post voiding residual urine, transrectal ultrasound of the prostate was done to measure the actual prostatic volume.

The study protocol had been approved from the local ethical committee at our hospital and a written informed consent was obtained from all patients. All patients were given broad spectrum antibiotics preoperative. Patient lied in the lithotomy position under spinal anesthesia. Diagnostic urethrocystoscopy was done for evaluating prostate size and any intravesical abnormality.

The epTURP Procedure was undertaken according to Alloussi et al. (2014) where preserved $1 \mathrm{~cm}$ proximal of the verumontanum and 2-3 $\mathrm{mm}$ gap bilaterally from the verumontanum (paracollicular tissue) to preserve ejaculatory ducts, then complete TURP as traditional technique.

All patients were intraoperatively observed for the following parameters: Operative time, blood transfusion if needed, intraoperative field of vision (clarity of field of vision), perforation, extravasation, and any other practical observations.

Early postoperative evaluation: Bedside assessment focused on volume of the irrigant. post-operative bleeding (severity and duration), hospital stay, duration of catheter indwelling, clot retention, rehospitalization for secondary hemorrhage or acute retention of urine and early severe irritative symptoms.

Assessment of the results was done by following up the patients postoperatively at $1,3,6$ months by IPSS, IIEF, ultrasound postvoiding residual urine, uroflowmetry, and semen volume estimation.

Statistical Analysis: Data were collected, revised, coded and entered to the Statistical Package for Social Science (IBM SPSS) version 23. The quantitative data were presented as mean, standard deviations and ranges when their distribution found parametric and also qualitative data were presented as numbers and percentages. The comparison between more than two paired groups with quantitative data and parametric distribution were done by using Repeated Measures ANOVA test followed by post hoc analysis using Bonferoni correction when the results were found significant.

Spearman correlation coefficients were used to assess the correlation 
between two quantitative parameters in the same group. The confidence interval was set to $95 \%$ and the margin of error accepted was set to $5 \%$. So, the p-value was considered significant when $\mathrm{P}$-value $<0.05$.

\section{RESULTS}

Overall, 34 consecutively enrolled patients with $\mathrm{BOO}$ and with the ability to preserve antegrade ejaculation were included in the study. Three patients discontinued, two died after one, and five months of the operation due to ischemic coronary heart attack, and the third was diagnosed prostate cancer on pathological examination of the prostatic chips after TURP.

The patients were treated with transurethral resection of the prostate using monopolar TURP with glycine irrigation solution. Data were collected in the pre and postoperative period at $1,3,6$, months. The preoperative and postoperative data were analyzed and compared.

Demographic data of the 31 studied patients: The patients aged on average
58.97 years, and had a standard deviation 6.06. The patients had a prostatic volume on average $62.29 \mathrm{ml}$, with a standard deviation 13.11. Anterograde ejaculation was preserved in 27 patients of the 31 patients $(87 \%)$. Three patients did not ejaculate on follow up after epTURP at 1 , 3, 6 months, and 27 patients ejaculate semen volume ranged from 0.5 to $3.5 \mathrm{ml}$. the 4th failed case did not void after removal of the catheter, and needed reintervention by the conventional standard TURP.

There was a statistically significant decrease in semen volume in the studied patients at 1 month post-operative $(1.40 \pm$ $0.84)$, than before operation $(2.19 \pm 0.82)$, then showed improvement at 3,6 months post-operative $(1.81 \pm 1.05),(1.89 \pm 1.06)$ respectively (Table $\mathbf{1})$.

Table (1): The change in semen volume before and post epTURP at 1, 3, and 6 months

\begin{tabular}{|c|c|c|c|c|c|c|}
\hline Semen volume & Range & Mean \pm SD & P-value ${ }^{1}$ & $\mathbf{P}^{2}$ & $\mathbf{P}^{3}$ & $\mathbf{P}^{4}$ \\
\hline Before operation & $1-4$ & $2.19 \pm 0.82$ & -- & \multirow{4}{*}{0.001} & \multirow{4}{*}{0.001} & \multirow{4}{*}{0.005} \\
\hline 1 month & $0-3$ & $1.40 \pm 0.84$ & 0.000 & & & \\
\hline 3 months & $0-4$ & $1.81 \pm 1.05$ & 0.000 & & & \\
\hline 6 months & $0-4$ & $1.89 \pm 1.06$ & 0.002 & & & \\
\hline Repeated measures ANOVA & \multicolumn{6}{|c|}{42.293} \\
\hline P-value ${ }^{0}$ & \multicolumn{6}{|c|}{$<0.001$} \\
\hline
\end{tabular}

$\mathrm{P}^{0}$ : Comparison between the four times using repeated measures ANOVA followed by post hoc analysis by Bonferoni correction

$\mathrm{P}^{1}$ : Each time vs before operation; $\mathrm{P}^{2}$ : 1 month vs 3 months; $\mathrm{P}^{3}: 1$ month vs 6 months; $\mathrm{P}^{4}: 3$ month vs 6 months

There was a statistically significant increase in $\mathrm{Q}$ max in the studied patients at 1 month $(15.76 \pm 4.98)$ and at 3 months $(17.73 \pm 5.96)$ and also at 6 months
$(18.60 \pm 5.93)$ than before operation $(4.84$ \pm 3.82) (Table 2). 
Table (2): The change in $Q$ max before and post epTURP at 1, 3, and 6 months

\begin{tabular}{|c|c|c|c|c|c|c|}
\hline Q max & Range & Mean \pm SD & P-value ${ }^{1}$ & $\mathbf{P}^{2}$ & $\mathbf{P}^{3}$ & $\mathbf{P}^{4}$ \\
\hline Before operation & $0-10 \mathrm{ml} / \mathrm{s}$ & $4.84 \pm 3.82$ & -- & \multirow{4}{*}{0.001} & \multirow{4}{*}{0.001} & \multirow{4}{*}{0.017} \\
\hline 1 month & $0-22 \mathrm{ml} / \mathrm{s}$ & $15.76 \pm 4.98$ & 0.000 & & & \\
\hline 3 months & $0-25 \mathrm{ml} / \mathrm{s}$ & $17.73 \pm 5.96$ & 0.000 & & & \\
\hline 6 months & $0-25 \mathrm{ml} / \mathrm{s}$ & $18.60 \pm 5.93$ & 0.000 & & & \\
\hline Repeated measures ANOVA & \multicolumn{6}{|c|}{163.147} \\
\hline P-value ${ }^{0}$ & \multicolumn{6}{|c|}{$<0.001$} \\
\hline
\end{tabular}

$\mathrm{P}^{0}$ : Comparison between the four times using repeated measures ANOVA followed by post hoc analysis by Bonferoni correction

$\mathrm{P}^{1}$ : Each time vs before operation; $\mathrm{P}^{2}: 1$ month vs 3 months; $\mathrm{P}^{3}: 1$ month vs 6 months; $\mathrm{P}^{4}: 3$ month vs 6 months

There was a statistically significant decrease in Post voiding residual urine in the studied patients at 1 month $(45.90 \pm$ 53.09), 3 months (40.35 \pm 55.87$)$ and also at 6 months 34.29 \pm 49.59) than before operation (166.87 \pm 90.67) (Table 3).

Table (3): Postvoiding residual urine before and post epTURP at 1, 3, and 6 months

\begin{tabular}{|c|c|c|c|c|c|c|}
\hline Post voiding residual urine & Range & Mean \pm SD & P-value ${ }^{1}$ & $\mathbf{P}^{2}$ & $\mathbf{P}^{3}$ & $\mathbf{P}^{4}$ \\
\hline Before operation & $52-430 \mathrm{ml}$ & $166.87 \pm 90.67$ & -- & \multirow{4}{*}{0.003} & \multirow{4}{*}{0.001} & \multirow{4}{*}{0.001} \\
\hline 1 month & $18-270 \mathrm{ml}$ & $45.90 \pm 53.09$ & 0.000 & & & \\
\hline 3 months & $12-270 \mathrm{ml}$ & $40.35 \pm 55.87$ & 0.000 & & & \\
\hline 6 months & $12-250 \mathrm{ml}$ & $34.29 \pm 49.59$ & 0.000 & & & \\
\hline $\begin{array}{c}\text { Repeated measures } \\
\text { ANOVA }\end{array}$ & \multicolumn{6}{|c|}{65.253} \\
\hline P-value ${ }^{0}$ & \multicolumn{6}{|c|}{$<0.001$} \\
\hline
\end{tabular}

$\mathrm{P}^{0}$ : Comparison between the four times using repeated measures ANOVA followed by post hoc analysis by Bonferoni correction

$\mathrm{P}^{1}$ : Each time vs before operation; $\mathrm{P}^{2}: 1$ month vs 3 months; $\mathrm{P}^{3}: 1$ month vs 6 months; $\mathrm{P}^{4}: 3$ month vs 6 months

There was a statistically significant decrease in IPSS in the studied patients at 1 month (7.45 \pm 6.40$)$, at 3 months $(5.29 \pm$
6.72) and also at 6 months (3.74 \pm 6.88$)$ than before operation $(23.10 \pm 4.83)$ (Table 4).

Table (4): IPSS before operation and follow up after 1, 3, and 6 months

\begin{tabular}{|c|c|c|c|c|c|c|}
\hline IPSS & Range & Mean \pm SD & P-value ${ }^{1}$ & $\mathbf{P}^{2}$ & $\mathbf{P}^{3}$ & $\mathbf{P}^{4}$ \\
\hline Before operation & $14-30$ & $23.10 \pm 4.83$ & -- & \multirow{4}{*}{0.001} & \multirow{4}{*}{0.001} & \multirow{4}{*}{0.001} \\
\hline 1 month & $2-30$ & $7.45 \pm 6.40$ & 0.000 & & & \\
\hline 3 months & $\mathbf{1 - 3 0}$ & $5.29 \pm 6.72$ & 0.000 & & & \\
\hline 6 months & $\mathbf{0}-\mathbf{3 0}$ & $3.74 \pm 6.88$ & 0.000 & & & \\
\hline Repeated measures ANOVA & \multicolumn{6}{|c|}{207.751} \\
\hline P-value ${ }^{0}$ & \multicolumn{6}{|c|}{$<0.001$} \\
\hline
\end{tabular}

$\mathrm{P}^{0}$ : Comparison between the four times using repeated measures ANOVA followed by post hoc analysis by Bonferoni correction

$\mathrm{P}^{1}$ : Each time vs before operation; $\mathrm{P}^{2}$ : 1 month vs 3 months; $\mathrm{P}^{3}: 1$ month vs 6 months; $\mathrm{P}^{4}: 3$ month vs 6 months 
HANY M. HENDY et al.,

There was no significant change in IIEF in the studied patients at 1 month (55.61 \pm 16.55$), 3$ months $(57.65 \pm 16.64)$ and also at 6 months $(59.48 \pm 16.94)$ than before operation $(60.42 \pm 8.46)$ (Table 5).

Table (5): IIEF before operation and follow up after 1, 3, and 6 months

\begin{tabular}{|c|c|c|c|c|c|c|}
\hline IIED & Range & Mean \pm SD & P-value ${ }^{1}$ & $\mathbf{P}^{2}$ & $\mathbf{P}^{3}$ & $\mathbf{P}^{4}$ \\
\hline Before operation & $44-73$ & $60.42 \pm 8.46$ & -- & \multirow{4}{*}{0.000} & \multirow{4}{*}{0.000} & \multirow{4}{*}{0.000} \\
\hline 1 month & $0-72$ & $55.61 \pm 16.55$ & 0.050 & & & \\
\hline 3 months & $0-72$ & $57.65 \pm 16.64$ & 0.266 & & & \\
\hline 6 months & $0-72$ & $59.48 \pm 16.94$ & 0.718 & & & \\
\hline Repeated measures ANOVA & \multicolumn{6}{|c|}{2.870} \\
\hline P-value ${ }^{0}$ & \multicolumn{6}{|c|}{0.096} \\
\hline
\end{tabular}

$\mathrm{P}^{0}$ : Comparison between the four times using repeated measures ANOVA followed by post hoc analysis by Bonferoni correction

$\mathrm{P}^{1}$ : Each time vs before operation; $\mathrm{P}^{2}$ : 1 month vs 3 months; $\mathrm{P}^{3}: 1$ month vs 6 months; $\mathrm{P}^{4}: 3$ month vs 6 months

In this study, during the early postoperative period, only 7 patients $(22.6 \%)$ had clot urinary retention in the presence of urethral catheter. all of them managed by flushing of urethral catheter without complication. 9 patients (29\%) suffered from early severe irritative symptoms following catheter removal, in the form of burning micturition, urgency and urge incontinence, 3 of these patients treated by anticholinergics for 10 days, the remaining patients had mild to moderate dysuria and resolved with antiinflammatory medication for one week. One patient (3.2\%) had been rehospitalized later after discharge due to secondary hemorrhage and he was managed by giving them IV fluid, IV antibiotics and hemostatic measures, no patient necessitated blood transfusion. No post TUR syndrome is recorded in our patients (Table 6).

\section{Table (6): Early postoperative complications}

\begin{tabular}{|c|c|c|}
\hline Early postoperative complications & NO. of affected patients & Percentage \\
\hline Clot retention & 7 patients & $\mathbf{2 2 . 6 \%}$ \\
\hline Early severe irritative symptoms & 9 patients & $\mathbf{2 9 \%}$ \\
\hline Re-hospitalization for secondary Hge & One patient & $\mathbf{3 . 2 \%}$ \\
\hline Post TUR syndrome & $\mathbf{0}$ & $\mathbf{0}$ \\
\hline
\end{tabular}

During follow up visits later on after 1, 3 and 6 months, our patients did not report any late complications as urethral stricture, bladder neck sclerosis. Three patients $(9.7 \%)$ can't ejaculate on follow up after epTURP at 1,3,6 months. the 4th failed case did not void after removal of catheter, and needed reintervention by traditional TURP. Early post operatively two patients complained of mild weakness of erection at one month post operatively, who improved at 3 months and completely cured at 6 months of follow up (Table 7). 
Table (7): Late postoperative complications.

\begin{tabular}{|c|c|c|}
\hline late postoperative complications:- & NO. of affected patients & Percentage \\
\hline Stress incontinence & 2 patients & $\mathbf{6 . 5 \%}$ \\
\hline Urethral stricture, bladder neck sclerosis & $\mathbf{0}$ & $\mathbf{0 \%}$ \\
\hline Loss of ejaculation & $\mathbf{3}$ patients & $\mathbf{9 . 7 \%}$ \\
\hline Loss of erection & $\mathbf{0}$ & $\mathbf{0}$ \\
\hline Retention & 1 & $3.2 \%$ \\
\hline
\end{tabular}

\section{DISCUSSION}

According to (EAU) the European Association of Urology Guidelines, the monopolar transurethral resection of the prostate (TURP) still represents the "gold standard" therapeutic approach in cases of average size BPH (between 30and $80 \mathrm{~mL}$ ) with indication for surgery (Gravas et al., 2019), with a possibility of loss of antegrade ejaculation reaching $70 \%$ of cases, the use of alpha-receptor antagonists is also known to possibility cause a loss in antegrade ejaculation (Gilling et al., 2018), consequently the epTURP technique was developed with the aim of preserving antegrade ejaculation.

Regarding initial data, the average age of our patients was 59 years. The average prostatic volume was $62.29 \mathrm{ml}$. It's comparable with Alloussi et al. (2014) the patients were aged on average 59.5 years and had average prostatic volume of 60.4 ml. Kim et al. (2014) stated that age average was 67 years and had an average aprostatic volume $62.5 \mathrm{ml}$.

In our study, antegrade ejaculation was preserved in $87 \%$ with antegrade ejaculation ability prior undergoing the epTURP procedure, at 6 months of the last follow up versus $20 \%$ after conventional TURP, in whom mostly the surgeons unintentially preserved the area of ejaculatory ducts to preserve the external urinary sphincter (Jaidane et al., 2010).
The same technique was described by Mohanned (2018) resulted in the maintenance of antegrade ejaculation in over $96 \%$ of treated patients. A comparable technique was prescribed by Kim et al. (2014) with $46.2 \%$ preservation of antegrade ejaculation. They used holmium laser enucleation of prostate with the same technique of preservation of ejaculatory ducts and $1 \mathrm{~cm}$ safety area proximal to verumontanum of prostate.

In our study, there was some decrease in semen volume at one month postoperatively, then improved at six months of follow up of our patients. Alloussi et al. (2014) and Arvind et al. (2018) showed no interest to measure semen volume accurately pre and post operatively, and evaluated their results of ejaculation preservation by IIEF, and the patient history of the ability to ejaculate.

Data on efficacy had been measured by the impact on, $\mathrm{Q}$ max, post voiding residual urine, IPSS, IIEF as well as QoL score, compared to baseline, was provided at follow-up periods ranging from 1 to 6 months.

In agreement with the other studies, our results showed that, there was a statistically significant increase in Q max in the studied patients post operatively at 1, 3, and 6 months than before operation. Mohanned (2018) showed that Q $\max$ increased from $5.4 \mathrm{ml} / \mathrm{s}$ to $21 \mathrm{ml} / \mathrm{s}$. Also, 
Alessandro et al. (2013) showed more better improvement in $\mathrm{Q} \max$, which increased from $7.4 \mathrm{ml}$ to $23.6 \mathrm{ml} / \mathrm{s}$ at one year follow-up.

In our study, there was a statistically significant decrease in (PVR) post voiding residual urine in the studied patients post operatively, at 1, 3 and at 6 months than before operation.

Our study was comparable to Kim et al. (2014), where PVR dropped from 103 $\mathrm{ml}$ pre operatively to $10.7 \mathrm{ml}$ post epTURP. Mohanned (2018) showed PVR decreased from $150 \mathrm{ml}$ pre operatively to $22 \mathrm{ml}$ post operatively at 3 months.

Our study showed a statistically significant decrease in IPSS in the studied patients at 1, 3 and at 6 months than before operation. Similar results were recorded in Alessandro et al. (2013), where IPSS total score dropped from 21.4 \pm 10.0 to $5.3 \pm 3.0$ at 3 months post operatively. Also Alloussi et al. (2014) reported a drop in IPSS total score from $22.8 \pm 4.8$ preoperatively to $4.5 \pm 3.3$, post epTURP.

With the agreement of the aim of our study, there was no significant change in IIEF in the studied patients at 1, 3 and at 6 months than before operation. No erectile dysfunction was recorded at the end of follow up of the patients at 6 months, while early post operatively two patients complained of mild weakness of erection at one month post operatively, who improved at 3 months and completely cured at 6 months of follow up. Alloussi et al. (2014) stated that, all parameters of IIEF were not affected. Also, Arvind et al. (2018) recorded normal sexuality and the relationships in general improved.
Early post operatively, two patients in our study complained of mild weakness of erection at one month post operatively, who improved at 3 months and completely cured at 6 months of follow up, we considered a temporary nerve insult from the thermal effect of the monopolar energy may be the cause, which may need more research.

In agreement with our study, Frieben et al. (2010) showed an improvement of the erectile function in men affected by erectile dysfunction and LUTS associated to BOO after endoscopic prostatectomy, no erection impairment was recoded in Alessandro et al. study (2013), Amang and Henry (2015) reported preservation of sexual function after epTURP.

As a normal sequel to the success of the new technique (epTURP) to relieve the distress and the complaint of the benign enlarged prostate, and preserve antegrade ejaculation and erectile function, there was a statistically significant improvement in QOL in the studied patients at 1, 3 and 6 months than before the operation.

The complications such as stress incontinence, urethral stricture and bladder-neck contracture were not recorded in our studied patients. $9.7 \%$ did not ejaculate on follow up after epTURP at 1, 3, 6 months. There was a failed case that did not void after removal of the urethral catheter, and needed reintervention by the traditional TURP. We considered the cause as imperfect resection of supra montanal tissue. 


\section{CONCLUSION}

The epTURP technique appeared as an effective minimally invasive procedure for patients with severe urinary obstructive symptoms due to benign prostatic enlargement and hope of preserving ejaculation. Longer follow up of the cases more than 6 months postoperatively may be required to assess the possibility of obstructive symptoms recure with the new technique of epTURP.

\section{REFERENCES}

1. Alloussi S, Lang C and Eichel R. (2014): Ejaculation-preserving transurethral resection of prostate and bladder neck. Journal of Endourology, 28 (1): 84-89.

2. Alessandro D, Stefano M, Pietro S, Giuseppe $P$ and Carlo V. (2013): TURP in the young man: is it possible to preserve the anterograde ejaculation? J Urol. 80 (1): 6469.

3. Amang $C$ and Henry H. (2015): Preservation of sexual function while relieving benign prostatic obstruction surgically: Can a trad- off be considered?, Current opinion in Urology, 25: 23-26.

4. Arvind J, Shabeeh $N$ and Devendra $D$. (2018): Chirayu medical college and hospital Bhopal, India. International Journal of Orthopedics Traumatology, Surgical Sciences, 4 (1): 23-26.

5. Chandrasekera S, De Zylva S, Lamahewage $N$. and Kulasinghe $M$. (2012): Ejaculation preserving transurethral resection of prostate: a pilot study. J Urol., 187 (4): 813-819.

6. Dogan B, Canda AE and Akbulut $Z$. (2011): Prostatic cyst causing severe infravescical obstruction in a young patient. J Urol., 8: 330-2.

7. Frieben RW, Lin HC, Hinh PP, Berardinelli F, Canfield SE and Wang R. (2010): The impact of minimally invasive surgeries for the treatment of symptomatic benign prostatic hyperplasia on male sexual functions: a systematic review. Asian $\mathrm{J}$ Androl., 12(4):500-8.

8. Gilling $P$, Barber N, Barber N, Bidair M, Anderson P, Sutton $M$, Thomas $A$ and Cowan B. (2018): A Double-Blind, Randomized, Controlled Trial of Aquablation vs Transurethral Resection of the Prostate in Benign Prostatic Hyperplasia. J Urol., 199: 1252-1261.

9. Girgin C, Oder M, Oguz Sahin M, Sezer A, Berkmen S, Aydin $R$ and Dincel $C$. (2013): Erection and Ejaculation-Preserving Cystectomy With Orthotopic Urinary Diversion Journal of Andrology, 27 (2): 558564.

10. Gravas S, Cornu, J.N, Gacci M, Gratzke C, Sakalis V and Umbach R. (2019): Management of Benign Prostatic Obstruction. EAU Guidelines, 9: 26-29.

11. Hsiao W, Deveci S and Mulhall J. (2012): Management of post-chemotherapy retroperitoneal lymph node dissectionassociated anejaculation. J BJUI, 110 (8): 2634.

12. Jaidane M, Arfa NB, Hmida W, Hidoussi A, Slama A and Sorba NB. (2010): Effect of transurethral resecction of the prostate on erectile function: a prospective comparative study. Int J Impot Res., 22: 146-151.

13. Kim M, Song SH, Ku JH, Kim $\mathrm{H}$ and Paick J. (2014): The clinical efficacy of ejaculatory hood sparing technique for ejaculation preservation in Holmium laser enucleation of the prostate. International Journal of Impotence Research, 27: 20-24.

14. Mohanned H. M. (2018): Ejaculation Preserving Technique in TURP Is it safe?. Diyala Journal of Medicine, 15 (2): 104-111.

15. Paul S, Henry H, Tom $M$ and Muir G. (2014): Ejaculatory Dysfunction After Treatment For Lower Urinary Tract Symptoms, BJU International. 0408.R2, 186187.

16. Selman SH (2011): The McNeal prostatic anatomy of the ejaculatory ducts and the surrounding ducts ejaculatorus muscle. A review of Urology, 78:1224-8. 


\section{نتيجة استنصسال البروستاتا بالمنظار مع الحفاظ على القذف الر عند الرجال}

هانى مفيد زاهر هندى، السيد محمد موسى، ياسر على أحمد

قسم جراحة المسالك البولية، كلية الطب، جامعة الأزهر، القاهرة، مصر

E-mail: hanygtu@gmail.com

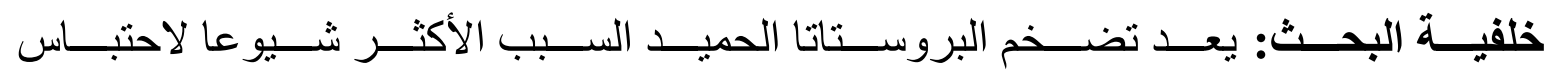

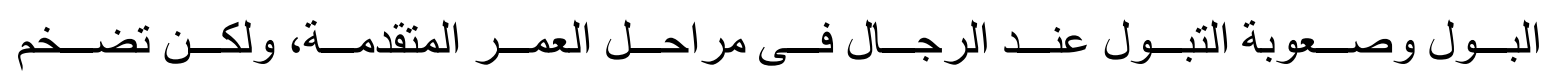

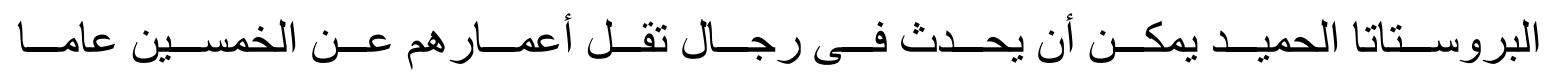

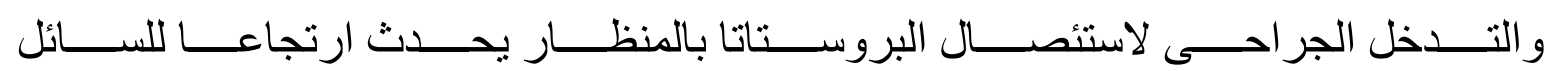

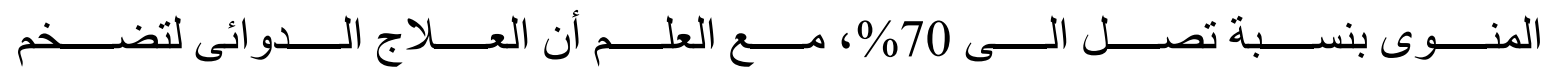

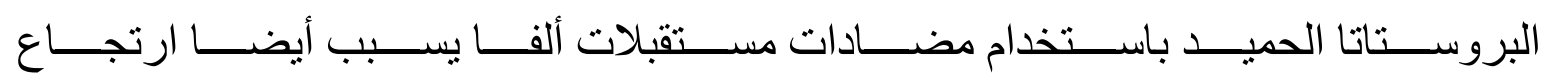
السائل المنوى عند القذف بنسبة كبيرة.

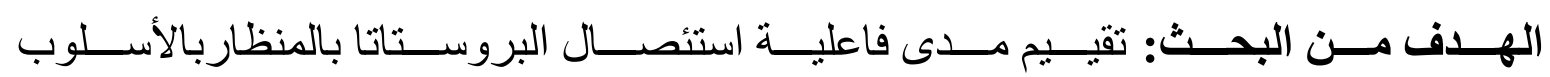
الجديد الذى يحافظ على القذف عند الرجال.

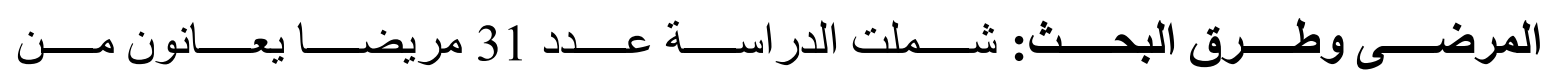

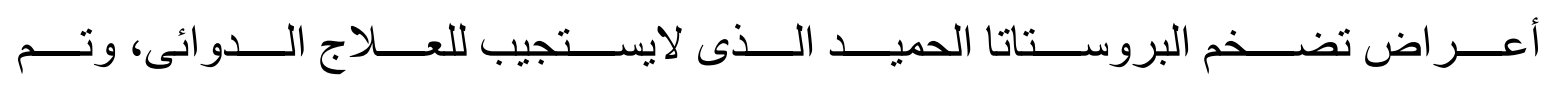

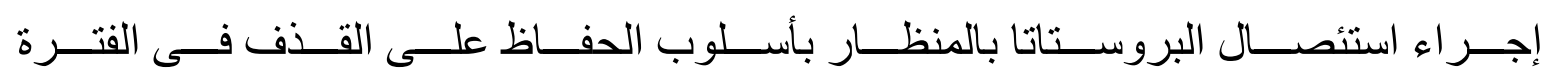

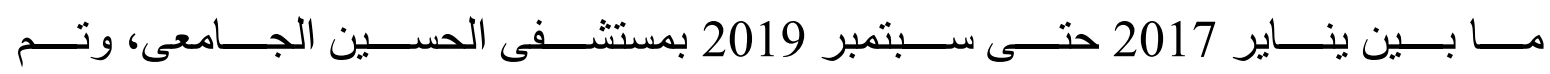

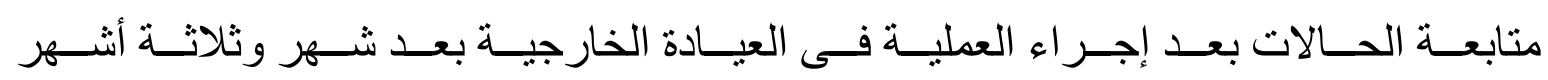

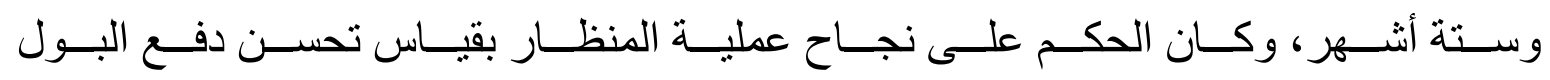

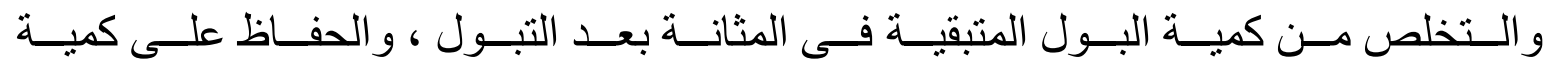

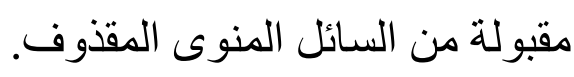

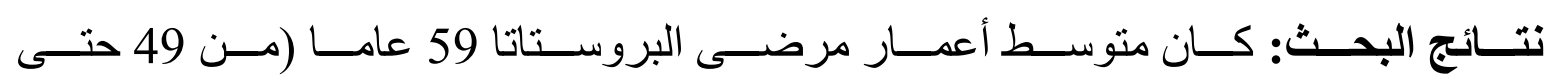

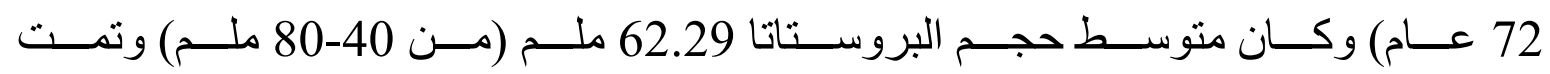




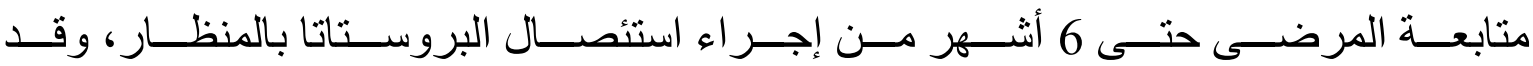

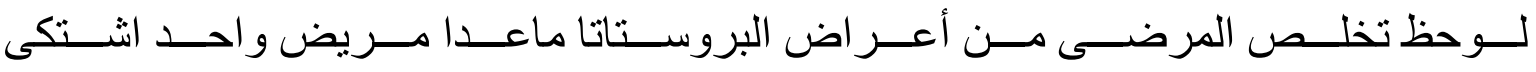

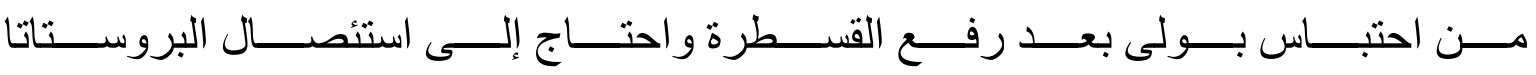

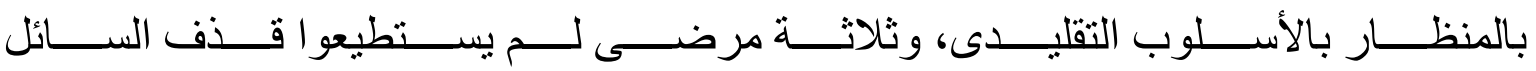
المنوى بعد متابعتهم بستة أثشهر من العملية.

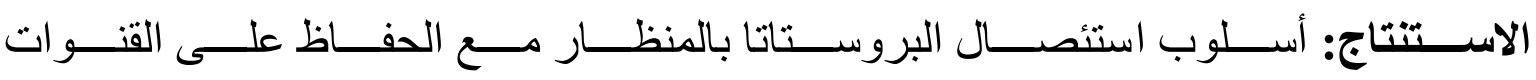

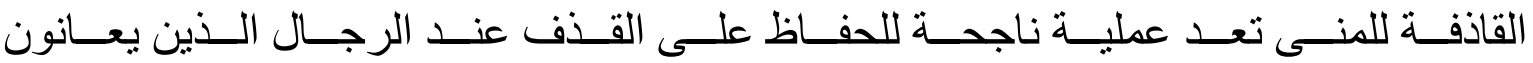

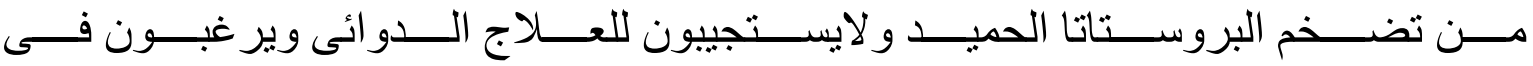

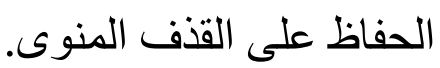

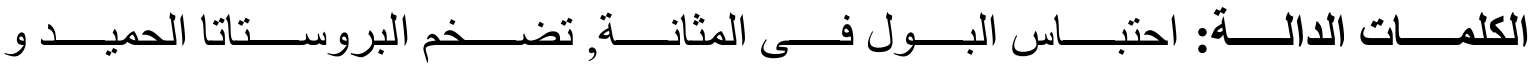
استئصسال البروستاتا بالمنظار مع الحفاظ على القنوات القاذفة. 